Revue d'histoire de l'Amérique française

QREVUE D.HISTOIRE DE L'AMÉRIQUE FRANÇAISE

\title{
Mourir chrétiennement
}

\section{La vie et la mort dans les établissements catholiques pour personnes âgées à Montréal au XIX ${ }^{\mathrm{e}}$ siècle}

\section{Bettina Bradbury}

Volume 46, numéro 1, été 1992

Montréal 1642-1992

URI : https://id.erudit.org/iderudit/305051ar

DOI : https://doi.org/10.7202/305051ar

Aller au sommaire du numéro

\section{Éditeur(s)}

Institut d'histoire de l'Amérique française

ISSN

0035-2357 (imprimé)

1492-1383 (numérique)

Découvrir la revue

Citer cet article

Bradbury, B. (1992). Mourir chrétiennement : la vie et la mort dans les établissements catholiques pour personnes âgées à Montréal au XIX ${ }^{\mathrm{e}}$ siècle. Revue d'histoire de l'Amérique française, 46(1), 143-175.

https://doi.org/10.7202/305051ar

\section{Résumé de l'article}

Cette étude porte sur les établissements pour malades, pauvres et personnes âgées dirigés par les Soeurs Grises et les Soeurs de la Providence à Montréal, au $\mathrm{XIX}^{\mathrm{e}}$ siècle. Se concentrant sur les pensionnaires de sexe féminin, âgées et veuves, elle brosse un portrait de la clientèle et en établit la durée du séjour, tout en évoquant la vie qu'elle y menait. Finir ses jours dans un asile ou un hospice présentait des avantages différents selon l'âge, l'infirmité, le sexe, les croyances et les relations avec la famille et les parents. L'hébergement dans ces institutions, où l'existence était imprégnée de religion, permettait de se préparer à faire une bonne mort, but proposé avec insistance aux catholiques. En outre, cette idée contribuait puissamment à légitimer le travail des religieuses et leur appel à la générosité du public. Car leur succès dépendait des liens qu'elles tissaient entre leurs oeuvres, leurs pauvres et l'ensemble de la communauté spirituelle et économique de Montréal. Ainsi la charité, complexe réseau économique et spirituel, unissait des gens que la classe, la fortune et les ressources spirituelles différenciaient.
Tous droits réservés Institut d'histoire de l'Amérique française, 1992
Ce document est protégé par la loi sur le droit d'auteur. L'utilisation des services d'Érudit (y compris la reproduction) est assujettie à sa politique d'utilisation que vous pouvez consulter en ligne.

https://apropos.erudit.org/fr/usagers/politique-dutilisation/ 


\title{
MOURIR CHRÉTIENNEMENT LA VIE ET LA MORT \\ DANS LES ÉTABLISSEMENTS CATHOLIQUES POUR PERSONNES ÂGÉES À MONTRÉAL AU XIX ${ }^{\mathrm{e}}$ SIÈCLE $^{1}$
}

\author{
BETTINA BRADBURY \\ Département d' histoire \\ Université de Montréal
}

\section{RÉSUMÉ}

Cette étude porte sur les établissements pour malades, pauvres et personnes âgées dirigés par les Sœurs Grises et les Sœurs de la Providence à Montréal, au XIX ${ }^{e}$ siècle. Se concentrant sur les pensionnaires de sexe féminin, âgées et veuves, elle brosse un portrait de la clientèle et en établit la durée du séjour, tout en évoquant la vie qu'elle y menait. Finir ses jours dans un asile ou un hospice présentait des avantages différents selon l'âge, l'infirmité, le sexe, les croyances et les relations avec la famille et les parents. L'hébergement dans ces institutions, où l'existence était imprégnée de religion, permettait de se préparer à faire une bonne mort, but proposé avec insistance aux catholiques. En outre, cette idée contribuait puissamment à légitimer le travail des religieuses et leur appel à la générosité du public. Car leur succès dépendait des liens qu'elles tissaient entre leurs œuvres, leurs pauvres et l'ensemble de la communauté spirituelle et économique de Montréal. Ainsi la charité, complexe réseau économique et spirituel, unissait des gens que la classe, la fortune et les ressources spirituelles différenciaient.

\section{ABSTRACT}

This paper examines the institutions run for the sick, poor and elderly in nineteenth century Montréal by the two major orders involved in catholic social work: the Grey Nuns and the Sisters of Providence. I focus mostly on women inmates, particularly widows. I look at the clientele and the amount of time they spent there, as well as the rhythm and texture of life within these institutions. Ending their lives

1 Cette recherche a été facilitée par une subvention pour les jeunes chercheurs du Fonds FCAR. Je voudrais plus particulièrement remercier Sœur Jeannine Blais, archiviste des Sœurs de la Providence et Sœur Gaétane Chevrier, des Sœurs Grises, pour leur accueil et l'aide qu'elles m'ont apportée au cours de mes travaux. Je veux également remercier Nathalie Picard et Sylvie 
in such an asile or hospice clearly offered different advantages to people, depending on their age, infirmity, sex, religious beliefs and their ties to family and kin. Life in an institution offered the possibility of living a religious life prior to death and increased the chances of receiving the religious support that guaranteed what was militantly promoted as a good death. Furthermore, that idea was a vital basis for the legitimation of the Nuns' work and for their demands for economic help. For their success depended on building up links between their works, their poor, and the wider spiritual and economic community of Montréal. Charity was a complex economic and spiritual relationship that bound together people of different classes, economic means and spiritual resources.

\section{INTRODUCTION}

Personne, semble-t-il, ne s'attendait à ce que Delphine Thoin meure ce matin-là. Certes, elle était très malade en cette fin de janvier 1880, mais elle ne semblait pas si proche de la fin qu'il faille faire venir le prêtre. Encore que les Sœurs de la Providence aient eu du mal à évaluer son état: Delphine n'était pas une patiente des plus faciles. Au cours du mois qu'avait duré sa maladie, elle avait demandé avec insistance à se confesser et à communier, tout en refusant de se rendre là où les malades allaient se confesser. La veille, l'aumônier était venu à son chevet et l'avait entendue en confession mais, étant prise de fréquents vomissements, elle n'avait pu communier. Le lendemain, sa messe à peine dite, l'abbé Dorion fut appelé à l'étage, dans le dortoir où logeaient les femmes âgées et malades. Il arriva trop tard: Delphine Thoin était déjà inconsciente, et c'est dans cet état qu'elle reçut l'extrême-onction.

Les circonstances entourant le décès de cette vieille plutôt capricieuse et difficile laissèrent la Communauté en proie à de vifs sentiments de culpabilité ${ }^{2}$. La mission première des Sœurs de la Providence consistait, en effet, à prendre soin des femmes âgées, des veuves en particulier. Depuis son veuvage, en 1827 , leur fondatrice, Émilie Gamelin, s'était vouée à cette tâche, qui resta la raison d'être de la congrégation après sa fondation officielle en $1843^{3}$. Depuis lors, les sœurs avaient accueilli plus de cinq cents femmes âgées et invalides,

Perrier qui ont assuré l'informatisation de la plupart des données et Olivette Genest pour ses commentaires théologiques et ses critiques de l'article. La citation est extraite d'un sermon du Père Rousselot, autrefois aumônier de la communauté et de l'Asile des pauvres des Sœurs Grises, prononcé le 22 octobre 1879 et cité dans les Archives des Sœurs Grises de Montréal (ASGM), «Circulaire Mensuelle» (CM), I: 437-438.

2 Archives Providence des Sœurs de la Providence (APSP), «Chronique de la maison mère, III, (1876-1881)»: 367-368; des sentiments du même ordre furent exprimés en 1884 à l'occasion du décès d'un pensionnaire de l'Asile Saint-Jean, géré par les Sœurs Grises, ASGM, CM, III: 48 .

3 Denise Robillard, Émilie Tavernier-Gamelin (Montréal, 1988), 93-171. 
qui presque toutes étaient mortes avec les sacrements de l'Église, reçus en pleine lucidité.

L'inquiétude manifestée par les religieuses à l'occasion de ce décès fait ressortir ce qu'elles et certaines de leurs pensionnaires considéraient comme l'un des avantages de finir ses jours dans un établissement religieux: les pauvres, les malades et les personnes âgées pouvaient s'attendre non seulement à y être nourris et soignés, mais aussi assistés par un prêtre dans leurs derniers moments. Ils pouvaient donc espérer faire une «bonne mort», une mort chrétienne ${ }^{4}$, ce qui était important aux yeux des sœurs comme des pensionnaires. Cependant, conformément à la structure du pouvoir religieux et à la division des tâches dans l'Église catholique, les sœurs n'assumaient qu'un rôle de soutien, seuls les prêtres étant habilités à administrer les sacrements.

J'étudierai, ici, au XIX ${ }^{\mathrm{e}}$ siècle, les établissements montréalais pour malades, pauvres et personnes âgées dirigés par les deux principales communautés engagées dans le service social: les Sœurs Grises et les Sœurs de la Providence. Je m'intéresserai surtout aux pensionnaires féminines et à la pratique des institutions caritatives du $\mathrm{XIX}^{\mathrm{e}}$ siècle de s'occuper des veuves autant que des femmes âgées. Je décrirai d'abord les transformations sociales et économiques les plus importantes survenues à Montréal des années 1830 aux années 1890. Je me pencherai ensuite sur la clientèle et la durée du séjour dans ces établissements. Puis je ferai revivre pour le lecteur l'atmosphère de ces établissements, en montrant comment on y vivait et mourait. Enfin, je tâcherai de dégager les liens économiques, spirituels et personnels qui unissaient ces établissements à l'ensemble de la communauté.

4 Dans une lettre pastorale datée du 27 avril 1877, Mgr Bourget décrit en quoi consiste une bonne mort. "Lettre pastorale de Mgr L'Évêque de Montréal, concernant les Catholiques qui, dans leurs maladies, vont se faire soigner à l'Hôpital-Général Protestant», Mandements, Lettres pastorales, Circulaires et Autres Documents publiés dans le Diocese de Montréal (Montréal, 1887), 7: 316. Pour des raisons de concision, je ne veux pas m'étendre ici sur la dimension théologique ou sur les attitudes populaires face à la mort; en outre, ces développements feraient appel à une historiographie différente. Sur la genèse du concept de bonne mort, on peut consulter Philippe Ariès, L'Homme devant la mort (Paris, Seuil, 1977), 299, 405442 et plus spécifiquement, sur le XIX ${ }^{e}$ siècle à Montréal, Brigitte Caulier, «Les Confréries de dévotion à Montréal au $19^{c}$ siècle», thèse de $\mathrm{Ph} . \mathrm{D}$. (histoire), Université de Montréal, 1986, ainsi que Philippe Sylvain et Nive Voisine, Histoire du catholicisme québécois: Réveil et consolidation, 2: 1840-1898 (Montréal, Boréal Express, 1991), 340-341. Marie-Aimée Cliche affirme que l'enseignement de l'Église concernant la préparation à la mort a peu changé «entre le concile de Trente et celui de Vatican II»; voir «L'Évolution des clauses religieuses traditionnelles dans les testaments de la région de Québec au XIX ${ }^{\bullet}$ siècle», Benoît Lacroix et Jean Simard, Religion populaire. Religion de clercs? (Québec, Institut québécois de recherche sur la culture, 1984), 367. 
Finir ses jours dans un asile ou un hospice présentait des avantages différents selon l'âge, l'infirmité, le sexe, la religion et les rapports avec la famille et les proches. Négligeant la dimension spirituelle, les historiens ont mis l'accent sur la pauvreté comme motif d'entrée dans ces établissements et sur la logique de contrôle social qui présidait à leur création et à leur administration. Je voudrais souligner dans cet article l'importance pour certains pensionnaires des soins spirituels qui accompagnaient les soins matériels. La vie dans un établissement religieux permettait de passer ses dernières années chrétiennement et de compter presque à coup sûr sur les secours de l'Église pour faire une bonne mort, but de tout catholique. En outre, les sœurs et la Hiérarchie accordaient de l'importance à ces considérations, qui légitimaient leur travail et justifiaient leur appel à la générosité du public. Car leur succès dans la promotion du catholicisme et dans la gestion d'un réseau complexe d'institutions de charité dépendait des liens qu'ils pouvaient établir entre leur activité, leurs pauvres et l'ensemble de la communauté spirituelle et économique de Montréal. L'action caritative s'inscrivait dans un système économique et spirituel où se rencontraient des individus qui différaient par la classe sociale, les moyens financiers et les ressources spirituelles.

L'histoire canadienne et québécoise s'est peu intéressée aux personnes âgées ${ }^{5}$. À Montréal, par exemple, nous en savons plus sur les enfants qui ont passé un certain temps dans des institutions que sur les personnes âgées ${ }^{6}$. Dans la société laïcisée d'aujourd'hui, la plupart

$5 \quad$ Ailleurs, on s'intéresse de plus en plus aux questions touchant les personnes âgées. Pour un aperçu critique de la documentation disponible et des principaux sujets discutés, on peut consulter Peter Stearns et David Van Tassel, «Introduction: Themes and Prospects in Old Age History», et Brian Gratton, «The New History of the Aged: a Critique», David Van Tassel et Peter N. Stearns, eds., Old Age in a Bureaucratic Society. The Elderly, the Experts, and the State in American History (New York, Greenwood Press, 1986); Peter N. Stearns, Old Age in European Society (Londres, Croom Helm, 1977); A.-E. Imhof, J.-P. Goubert, A. Bideau et M. Garden, Le vieillissement. Implications et conséquences de l'allongement de la vie humaine depuis le XVIII' siècle (Lyon, Presses de l'Université de Lyon, 1982); Andrew Cherlin, «A Sense of History: Recent Research on Aging and the Family», M. Riley, B. Hess et K. Bond eds., Aging in Society. Selected Reviews of Recent Research (New Jersey, Lawrence Erlbaum, 1983); J. S. Quadagno, Aging in Early Industrial Society: Work, Family and Social Policy in Nineteenth Century England (New York, Academic Press, 1982); David Radcliffe, "Growing Old in Ontario: a Gray Area», David Gagan et Rosemary Gagan, eds., New Directions for the Study of Ontario's Past (Hamilton, 1988).

6 Peter Gossage, «Les enfants abandonnés à Montréal au $19^{e}$ siècle: la Crèche d'Youville des Sœurs Grises, 18.20-1871», Revue d'histoire de l'Amérique française, 40,4 (printemps 1987): 537-559; Micheline Dumont, «Des garderies au XIX ${ }^{\bullet}$ siècle: les Salles d'asile des Sœurs Grises à Montréal», RHAF, 34,1 (juin 1980): 27-55; Bettina Bradbury, «The Fragmented Family: Family Strategies in the Face of Death, Illness, and Poverty, Montreal, 1860-1885», Joy Parr, ed., Childhood and Family in Canadian History (Toronto, McClelland and Stewart, 1982); Huguette Lapointe-Roy, Charité bien ordonnée. Le premier réseau de lutte contre la pauvreté a Montréal au 19e siecle (Montréal, Boréal, 1987), 145-184. 
d'entre nous avons de la difficulté à nous situer par rapport à la spiritualité et à la religion, ainsi que par rapport à la mort. L'augmentation de l'espérance de vie, la médicalisation et l'institutionnalisation de la mort ont radicalement modifié les lieux et les manières de mourir, nous évitant ainsi d'être confrontés à celle-ci. Le XIX ${ }^{\mathrm{e}}$ siècle était bien différent. Si nous voulons comprendre ce que représentaient de tels établissements, nous devons savoir ce que l'au-delà et la religion signifiaient pour les gens de cette époque, et comment la peur de la mort et du jugement fut employée par les Églises protestante et catholique pour imposer le conformisme. Nous devons aussi comprendre les contraintes matérielles de la vie quotidienne des personnes âgées, ainsi que les limites de la famille comme structure de soutien dans une ville en pleine industrialisation. Pour y parvenir, il faut faire appel à l'histoire du vieillissement et de la vieillesse, à celle de la religion et de la mort, à l'histoire des établissements caritatifs, ainsi qu'à celle de la femme et de la famille. Aucune théorie générale traitant de l'enfermement ou du rôle des établissements pour personnes âgées comme adjuvants du contrôle social ne rend compte de la multiplicité et de la complexité des facteurs expliquant l'attrait qu'exerce la vie en institution sur les personnes âgées et sur d'autres secteurs de la société?.

Dans cet article, j'utilise trois sources principales: les registres des Sœurs Grises et des Sœurs de la Providence fournissent des renseignements sur l'âge, la religion et la durée du séjour des pensionnaires, ainsi que, le cas échéant, leur mort en établissement, leur congé ou leur transfert ${ }^{8}$; on trouve aussi dans les chroniques rédigées par les sœurs à l'usage de leur congrégation des indices qui nous renseignent sur la place occupée par les vieillards et les infirmes dans leurs établissements et qui nous permettent d'imaginer ce que pouvait y être la vie quotidienne ${ }^{9}$. Les annalistes, qui de toute façon étaient chargées

7 Je suis d'accord avec Olivier Faure qui affirme que le concept de contrôle social n'est pas très pertinent pour expliquer les raisons qui poussaient les personnes âgées à entrer dans de telles institutions ou le comportement qu'elles y adoptaient. "Les classes populaires face à l'hôpital à Lyon au XIX' siècle», Cahiers d' histoire, 26,3 (1981): 259.

8 Les registres suivants ont été systématiquement dépouillés. ASGM, Registre d'admission des pauvres, vol. II, 1797-1854 (G6/IR3); pour la période de 1828 à 1854: Registre d'admission des pauvres et des orphelins, 1854-1907 (Hospice Saint-Joseph) (L10/T6); Registre des pauvres et des orphelins, vol. III, 1854-1890 (G6/IR5); Registre d'admission des pauvres et des enfants trouvés, 1834-1945. Note dit «Aucun pensionnaires, pauvres seulement» (G6/IR9) et (L2/IR9); Registre $n^{\circ} 1$, Hospice Saint-Charles à Montréal (ouvert le $1^{\text {er }}$ mai 1877) (1877-1894) (L35/R1); Index du registre d'admission, 1861-1974 (Institut Nazareth). APSP, Montréal, Registre des femmes vieilles et infirmes de l'Asile de la Providence, Montréal, depuis 1830 (1830-1891); Registre des vieillards et infirmes de l'Asile de la Providence, Montréal, depuis 1849 (M2.43). Registre des élèves depuis 1861 à 1974.

9 J'attire une attention particulière sur les chroniques suivantes: ASGM, Ancien Journal, vol. I. «Notes sur l'Hôpital Général des Sœurs Grises de Montréal» depuis sa fondation 
d'autres tâches, n'avaient pas pour principale préoccupation de décrire la clientèle. Les événements privilégiés dans leurs récits nous donnent quand même un assez bon aperçu de la vie spirituelle et matérielle des sœurs comme de leurs pensionnaires. Malheureusement, ils nous renseignent peu sur ce que les pensionnaires elles-mêmes pensaient. Comme c'était le cas autrefois dans le peuple, beaucoup ne savaient pas écrire et peu de docurnents laissés par ceux qui le pouvaient nous sont parvenus. Nous sommes donc contraints de les étudier à travers la perception qu'en avaient les sœurs. La troisième source principale est constituée des relevés manuscrits des recensements décennaux qui $m$ 'ont permis de déterminer l'importance relative des établissements des Sœurs Grises et des Sœurs de la Providence, ainsi que d'évaluer la proportion de personnes âgées dans la clientèle.

\section{LA CROISSANCE DE MONTRÉAL ET LE DÉVELOPPEMENT DES ÉTABLISSEMENTS, 1820-1890}

Tôt au XIX ${ }^{\mathrm{e}}$ siècle, Montréal, devançant Québec, devenait la plus grande ville du Bas-Canada. À l'époque de la Confédération, elle était la métropole du Canada, son principal centre commercial et industriel. Sa population passa de plus de 22000 en 1825 à plus de 180000 en 1891 , au moment du dernier recensement du XIX ${ }^{\mathrm{e}}$ siècle. Entre ces deux dates, la migration interne et les vagues d'immigrants venus d'Irlande, d'Angleterre, d'Écosse et d'autres pays d'Europe façonnèrent une ville où les nouveaux arrivants se mêlaient aux familles de vieille souche ${ }^{10}$. L'immigration des Catholiques irlandais et l'exode rural des Canadiens français accrurent la population catholique, qui des deux tiers dans les années 1820-1830 atteignit les trois quarts dans les années 1850 , la proportion demeurant à peu près inchangée pour le reste de la période ${ }^{11}$. La plupart des autres habitants appartenaient

jusqu'en 1857 (1688-1857); Ancien Journal, vol. II, «Notes sur l'Hôpital Général des Sœurs Grises de Montréal», (1857-1867); Ancien Journal, vol. III (1867-1877); Circulaire Mensuelle, adressée aux diverses maisons de l'Institut, I: 1877-1880; Circulaire Mensuelle, II: 1881-1883; Circulaire Mensuelle, III: 1884-1887; Circulaire Mensuelle, IV: 1888-1892; Chroniques de l'Institut Nazareth; Chroniques Hospice Saint-Joseph (L10/H4) 1854-1892. Archives des Sœurs de la Providence (désormais, ASP): Chroniques de l'Asile de la Providence, Maison-Mère, Montréal, 1828-1864 (non paginé) dactylographié; $2^{\mathrm{e}}$ volume des Chroniques de la Providence maison-mère (inachevé) 1864-1872 (non-paginé) dactylographié; Chroniques de la maison-mère, II, 1864-1872; Chroniques de la maison-mère, III, 1876-1881 (manuscrit); Chroniques de la maison-mère, IV, 1881-1886.

10 Jean-Claude Robert, «Urbanisation et population: le cas de Montréal en 1861», RHAF, 35,4 (mars 1982): 523-535; «Montréal, 1821-1871. Aspects de l'urbanisation», thèse de Ph.D. (histoire), École des Hautes Études en Sciences Sociales, Paris, 1977); Bettina Bradbury, Working Families. Age, Gender and Daily Survival in Industrializing Montreal (à paraître, 1993).

11 Louis Rousseau, La prédication a Montréal de 1800 a 1830: approche religiologique (Montréal, Fides, 1976), 75-76; Working Families...; Brigitte Caulier, «Les confréries de dévotion», 464. 
à l'une ou l'autre des diverses Églises protestantes. L'augmentation de la population pousse les responsables et les fidèles de toutes les Églises à mettre sur pied de nouveaux établissements adaptés aux réalités d'une ville en pleine industrialisation et en offrant la possibilité d'un enseignement et d'un contrôle religieux.

La réorganisation des méthodes de production artisanale et industrielle, ainsi que l'expansion de la construction, amenèrent un nombre croissant de Montréalais à travailler comme salariés. La classe ouvrière devint la plus nombreuse; elle était divisée par des différences de savoir-faire, de salaire et de tradition. À cette époque où l'État ne se chargeait pas encore de l'assistance sociale, les familles représentaient le principal soutien des vieux et des jeunes, chez les riches comme chez les pauvres. En période de chômage, de maladie ou d'autres situations critiques, les membres d'une même famille se tournaient les uns vers les autres ainsi que vers la parentèle. Lorsque ce premier niveau d'appui faisait défaut, certains se tournaient vers les réseaux de bienfaisance des Églises. Il arrivait aussi à des représentants des Églises de parcourir les quartiers à la recherche de nécessiteux. Les personnes âgées sans famille ou dont les enfants et les proches étaient pauvres pouvaient bénéficier d'une aide à domicile sous forme de soins, de nourriture, de vêtements ou de réconfort spirituel. Les personnes que la maladie ou la sénilité rendaient incapables de prendre soin d'elles-mêmes, ou qui recherchaient un milieu plus tranquille et plus religieux, pouvaient choisir d'aller vivre dans l'un des asiles pour vieillards de la ville.

Cet article s'intéresse principalement à cette minorité de la population âgée qui finissait ses jours dans l'un de ces établissements ou y séjournait au moins quelque temps. Il ne faudrait cependant pas perdre de vue que la vie en institution n'a pas été le lot de la majorité des Montréalais âgés du XIX ${ }^{\mathrm{e}}$ siècle. Si nous prenons, par exemple, les veufs et les veuves, l'une des composantes de la population âgée, on voit qu'en 1861 seulement 4 ou $5 \%$ d'entre eux vivaient en institution avant l'âge de 70 ans. Entre 70 et 80 ans, c'était le cas d'une personne sur dix, alors qu'après 80 ans, $16 \%$ des veuves et $20 \%$ des veufs habitaient de façon relativement permanente dans un établissement lors du recensement (figure 1). La plupart mouraient chez leurs enfants ou leurs proches. Enfin, avant l'âge de 80 ans, les veufs comme les veuves étaient plus souvent en pension dans des familles que dans un quelconque établissement. 
Figure 1

Situation domiciliaire des veuves et des veufs suivant l'âge, Montréal (1861)

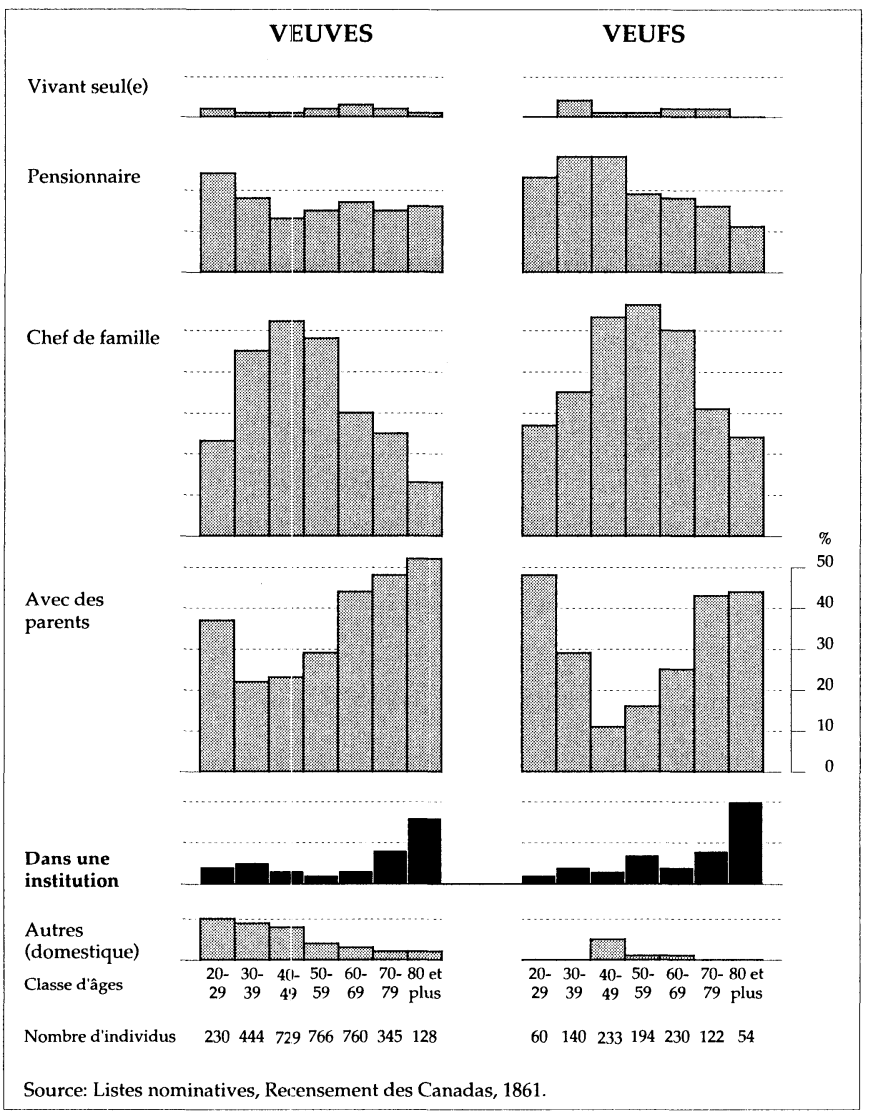




\section{LA CROISSANCE DES ÉTABLISSEMENTS}

Avec les années, on observe une augmentation du nombre des établissements offrant le gîte aux personnes âgées et invalides. La croissance rapide des communautés religieuses, dans le sillage de la montée du catholicisme ultramontain, dont Mgr Ignace Bourget s'était fait le promoteur zélé, fournit une véritable armée de travailleurs sociaux religieux à la population catholique grandissante de la ville. $\mathrm{Au}$ début du $\mathrm{XIX}^{\mathrm{e}}$ siècle, on s'occupait des personnes âgées surtout dans les grands hôpitaux catholiques et protestants, ainsi qu'à l'Hôpital Général des Sœurs Grises. À la fin du siècle, les Sœurs Grises avaient cinq hospices un peu partout dans la ville; les Sœurs de la Providence poursuivant l'œuvre entreprise dans les années 1840 par Émilie Gamelin, accueillaient par centaines les personnes âgées et les pauvres; enfin, de nouvelles congrégations comme les Petites Sœurs des Pauvres et les Sœurs de Sainte-Marthe abritaient aussi les personnes âgées ${ }^{12}$. Pour leur part, les protestants pouvaient trouver asile au Home of Industry and Refuge, au Ladies Benevolent Institute et dans une pléiade d'établissements de moindre importance. Ainsi, en 1881, plus du tiers des veuves vivant en institution étaient chez les Sœurs Grises, le cinquième chez les Sœurs de la Providence et à peine un peu plus au Protestant Home of Industry and Refuge ${ }^{13}$.

\section{LA CLIENTÈLE DES SEURS GRISES ET DES SEURS DE LA PROVIDENCE ET LE CHOIX DE VIVRE EN INSTITUTION}

Entre 1830 et 1890 , plus de 3000 femmes et quelque 2000 hommes passèrent un certain temps dans un des cinq hospices des Sœurs Grises ou à la maison mère des Sœurs de la Providence (tableau 1). La plupart étaient âgés et une large majorité avait dépassé 70 sinon 80 ans. L'âge moyen était d'environ 70 ans, soit un peu plus jeune que dans les établissements du même genre en France. Cependant, ces établissements n'étaient pas comme les hospices de vieillards qui existaient en France au XIX ${ }^{e}$ siècle et où les hommes et les femmes de moins de 70 ans avaient peu de chance d'être admis, la demande y excédant toujours le nombre de places disponibles ${ }^{14}$. Pour diverses

12 Listes nominatives (LN), recensement de 1891; Huguet-Latour, Annuaire de VilleMarie. Origine, utilité et progrès des institutions catholiques de Montréal (Montréal, Sénécal, 1863), 90.

13 LN, recensement de 1881 . On y indique le nombre de veuves dans chaque institution par rapport à l'ensemble des veuves en institution.

14 Maurice Garden, «Les hospices de vieillards. Du comité de mendicité à la loi d'Assistance obligatoire (1790-1905)», A.-E. Imhoff, Le vieillisement. Implications et conséquences de l'allongement de la vie humaine depuis le XVIII' siecle (Lyon, Presses universitaires de Lyon, 1979), 103-106; Olivier Faure, «Les classes populaires face à l'hôpital» (1981): 267. 


\section{Tableau 1}

\section{La clientèle adulte des Soeurs de la Providence et des Soeurs Grises, 1830-1890}

\begin{tabular}{|c|c|c|c|c|c|c|c|c|c|}
\hline \multicolumn{10}{|c|}{ A - Asile de la Providence } \\
\hline & \multicolumn{2}{|c|}{$\begin{array}{l}\text { Statut non } \\
\text { mentionné }\end{array}$} & \multicolumn{2}{|c|}{$\begin{array}{l}\text { Femmes } \\
\text { célibataires }\end{array}$} & \multirow{2}{*}{\multicolumn{2}{|c|}{$\begin{array}{c}\begin{array}{c}\text { Femmes } \\
\text { mariées }\end{array} \\
\text { Nombre \% }\end{array}$}} & \multicolumn{2}{|c|}{ Veuves } & \multirow[t]{2}{*}{ Totaux } \\
\hline & Nombre & $\%$ & Nombre & $\%$ & & & Nombre & $\%$ & \\
\hline $1830-1849$ & 29 & 22 & 32 & 24 & 3 & 2 & 70 & 52 & 134 \\
\hline $1850-1869$ & 38 & 18 & 78 & 36 & 43 & 20 & 57 & 26 & 216 \\
\hline $1870-1887$ & 11 & 5 & 86 & 39 & 35 & 16 & 90 & 41 & 222 \\
\hline $1888-1891$ & 5 & 2 & 82 & 40 & 28 & 14 & 90 & 44 & 205 \\
\hline Totaux & 83 & 11 & 278 & 36 & 109 & 14 & 307 & 40 & 777 \\
\hline Hommes & 125 & 80 & - & - & 5 & 3 & 25 & 16 & 155 \\
\hline \multicolumn{10}{|c|}{ B - Soeurs Grises ${ }^{*}$} \\
\hline $1830-1849$ & 68 & 58 & 1 & 1 & 4 & 3 & 45 & 38 & 118 \\
\hline $1850-1869$ & 487 & 71 & 15 & 2 & 31 & 5 & 154 & 22 & 687 \\
\hline $1870-1890$ & 672 & 39 & 138 & 8 & 201 & 12 & 693 & 41 & 1704 \\
\hline Totaux & 1227 & 49 & 154 & 6 & 236 & 9 & 892 & 36 & 2509 \\
\hline Hommes & 658 & 39 & 183 & 11 & 363 & 22 & 484 & 29 & 1688 \\
\hline
\end{tabular}

Les données suivantes ne concernent que quatre de leurs établissements: l'Asile des pauvres à la maison mère, l'hospice Saint-Joseph, l'hospice Saint-Charles et les résidants voyants de l'Asile Nazareth. Le Refuge Sainte-Brigitte est le plus important des établissements dont les données ne sont pas comptabilisées ici: ses registres ne sont pas dans les archives des Soeurs Grises. La comparaison de l'état civil noté dans ces registres avec les renseignements que fournit le recensement pour les mêmes personnes nous permet de déduire que la majorité de celles dont les religieuses n'indiquaient pas l'état civil étaient probablement célibataires.

Sources: $\quad$ ASGM, Registre d'admission des pauvres, vol. II, 1797-1854 (G6/IR3); Registre des pauvres et des orphelins, vol. III, 18:54-1890 (G6/IR5); Index du registre d'admission, 1861-1974 (Institut Nazareth); Registre d'admission des pauvres et des orphelins, 1854-1907 (Hospice Saint-Joseph) (L10/T6); Registre ${ }^{\circ} 1$, Hospice Saint-Charles à Montréal (ouvert le $1^{\text {er }}$ mai 1877) (1877-1894) (L35/R1); ASP, Registre des femmes vieilles et infirmes de l'Asile de la Providence, Montréal, depuis 1830 (1830-1891); Registre des vieillards et infirmes de l'Asile de la Providence de Montréal, 1849-1891. 
raisons, quelques hommes et femmes dans la vingtaine ou la trentaine cherchaient aussi refuge chez les sœurs, cohabitant avec les résidants âgés.

L'Asile de la Providence et l'Hôpital Général n'étaient ni des hôpitaux, ni de simples foyers pour personnes âgées ${ }^{15}$. C'étaient des asiles où l'on pouvait rester pour une courte période ou demeurer durant des années, jusqu'à sa mort même. Par exemple, à l'Hospice Saint-Charles, ouvert en 1877 par les Sœurs Grises, la durée du séjour variait de quatre jours à dix-sept ans. Pour les pensionnaires arrivés de 1877 à 1881 , le séjour moyen de ceux qui y étaient décédés était de plus de deux ans et celui de ceux qui en étaient repartis, de cinq à six mois ${ }^{16}$. Comme nous le verrons, la majorité de ceux qui entraient dans ces établissements y mouraient, mais cette proportion eut tendance à décroître avec les années.

On ne comprend aujourd'hui qu'en partie pourquoi ces hommes et ces femmes venaient vivre leurs dernières années dans ces établissements. Dans les registres d'entrées, on trouve parfois des indices révélateurs de leur état de santé physique ou mentale, des liens qu'ils entretenaient avec leur famille ou de leur expérience passée. Des notes laconiques identifient certaines femmes comme idiotes, épileptiques, «pulmonaires», paralytiques, aveugles ou ayant l'esprit troublé, nous permettant de déduire le genre d'affection qui pouvait empêcher leurs proches d'en prendre soin.

On indique parfois quels membres de la famille sont venus placer leurs parents âgés ou malades: un tel avait amené sa tante et avait payé sa pension ${ }^{17}$. On a vu un veuf se présenter avec sa fille et être accueilli parmi les hommes âgés tandis que sa fille allait rejoindre les orphelins, avant de devenir finalement religieuse, mais dans une autre communauté. D'autres avaient des sœurs, des tantes ou même des filles religieuses dans la communauté qui prenait soin d'eux ${ }^{18}$. On a relevé le cas d'une pauvre vieille femme abandonnée subrepticement à la porte de l'Asile de la Providence un soir, au début de décembre, et portant son nom et son âge épinglés sur ses vêtements. Après avoir raconté son histoire, elle implora avec succès son admission, offrant

15 À titre de comparaison, Maurice Garden décrit les hospices de Lyon au XIX ${ }^{e}$ siècle comme des «mouroirs». Maurice Garden, «Les hospices de vieillards. Du comité de mendicité à la loi d'Assistance obligatoire (1790-1905)», A.-E. Imhoff, ibid., 103-106.

16 ASGM, Registre $n^{\circ} 1$, Hospice Saint-Charles à Montréal (ouvert le $1^{\text {er }}$ mai 1877) (1877-1894).

17 ASGM, Registre des pauvres, 1845.

18 ASGM, CM, I, 1877-1880: 337; CM, II: 118; 391. 
de dormir à même le sol faute de place. Elle décéda peu de temps après ${ }^{19}$. Les deux communautés admettaient aussi comme pensionnaires des femmes disposant de quelque fortune. Elles partageaient étroitement la vie spirituelle et communautaire de la congrégation, contribuant souvent de leurs deniers à la décoration des chapelles, des autels et des églises ${ }^{20}$.

Gardons-nous de trop simplifier. Si certains choisissaient librement de séjourner quelque temps dans ces établissements, d'autres y étaient vraisemblablement forcés par leur famille qui ne pouvait ou ne voulait pas prendre soin d'eux. Si certains, encore, aspiraient à une vie paisible dans un contexte religieux, d'autres recherchaient plus prosaïquement la sécurité matérielle, des soins infirmiers, la nourriture et un bon lit. Enfin, la peur a pu inciter à chercher asile dans ces établissements certaines personnes âgées et malades, effrayées par les horribles descriptions de la mort, la perspective de mourir sans préparation suffisante et les horreurs de la damnation éternelle dont leur parlaient les prêtres ${ }^{21}$. Il est certain que des personnes étaient privées des autres sources de secours religieux, soit par l'infirmité, soit par les règles en vigueur. Par exemple, les femmes pauvres, âgées et malades, tout comme celles qui ne pouvaient lire, ne pouvaient appartenir à l'une ou l'autre des diverses confréries fondées en bonne partie pour assurer une bonne mort aux laïcs. Il est possible que des femmes dans une telle situation aient recherché auprès des sœurs un soutien social et religieux similaire ${ }^{22}$.

Des facteurs d'ordre familial, économique, spirituel ou médical jouaient un rôle majeur auprès des clients et de leurs proches. Ceux qui avaient de la famille en ville étaient les moins susceptibles de finir leurs jours en institution. Les célibataires, tant hommes que femmes, devaient affronter la vieillesse sans le soutien du système de sécurité

19 APSP, Chroniques, 1881-1886, 165-166.

20 Ibid., 27.

21 Les tentatives de terrorisme spirituel ont peut-être échoué auprès de l'ensemble de la population, malgré les terrifiantes descriptions de la mort, de la décomposition des corps et, surtout, de l'enfer qui caractérisaient certains sermons. En revanche, les vieillards et les malades semblent avoir été plus sensibles à ce genre d'évocations. Philippe Sylvain et Nive Voisine, Histoire du catholicisme québécois, II: Réveil et consolidation, 2: 1840-1898, 21, 307. Louis Rousseau affirme qu'au début du siècle, les fidèles de Montréal étaient conditionnés par la peur: d'après ce que prêchaient les Sulpiciens, peu d'entre eux pourraient être sauvés, La prédication à Montréal, 235.

22 Brigitte Caulier note qu'après 1871 la Confrérie Sainte-Famille de Montréal n'acceptait plus de femmes incapables de payer et que les analphabètes étaient généralement exclues, «Les confréries de dévotion», 91, 399. Sur le rôle que jouait la peur de la mort, voir, 327,340 . 
sociale le plus important au XIX ${ }^{e}$ siècle: les enfants ${ }^{23}$. Ils vieillissaient en même temps que leurs frères et sœurs et voyaient ainsi se réduire le cercle des proches sur lesquels ils pouvaient compter, contrairement à ceux qui étaient mariés. Le fait qu'une large proportion des résidants de ces établissements semble avoir été célibataire ne doit donc pas nous surprendre (tableau 1). Alors que les femmes célibataires ne dépassaient jamais les $20 \%$ de la population adulte, elles comptaient pour $40 \%$ des femmes résidant à l'Asile de la Providence entre 1888 et 1891. Ceux et celles qui étaient encore mariés étaient les moins susceptibles d'entrer en institution, les veuves comptant, globalement, pour un peu plus du tiers des personnes admises. Elles n'étaient pas toutes pauvres, mais la plupart l'étaient. En 1861, environ la moitié des veuves qui vivaient auprès de l'une ou l'autre congrégation étaient analphabètes ${ }^{24}$.

L'industrialisation de Montréal y attira, des régions avoisinantes, des gens à la recherche d'un travail salarié dans les manufactures ou sur les chantiers de construction, qui se multipliaient à mesure qu'on avançait dans le siècle; le réseau de plus en plus complexe d'institutions caritatives exerça le même effet. Les religieuses ne notaient pas toujours d'où venaient les gens. Cependant, entre 1877 et 1883, les Sœurs Grises de l'Hospice Saint-Charles notaient depuis combien de temps les nouvelles venues vivaient à Montréal, ce qui nous renseigne quelque peu sur leur lieu de résidence. Ainsi, plus de la moitié de celles qui ont passé un certain temps dans cet hospice vivaient à Montréal depuis au moins cinq ans; $40 \%$ y étaient depuis plus de vingt ans. Seul un petit groupe - environ une arrivante sur dix - semble être venu en ville à seule fin d'y chercher asile. La mention «à Montréal depuis ce jour» accompagnait l'inscription de ces femmes. Si les cas que nous venons de citer peuvent être représentatifs de l'ensemble de la clientèle de ces établissements, il faudrait donc en déduire que ces derniers s'adressaient surtout à la population montréalaise.

La politique des Sœurs Grises prévoyait l'admission des infirmes, hommes et femmes, sans distinction d'origine ou de croyance; elles ne notaient même pas la confession de leurs clients. Cependant, la majorité d'entre eux étaient catholiques et de bonnes mœurs. Ceux qu'on jugeait dangereux pour les autres résidants, comme les ivrognes

23 Tamara Hareven, «Life-Course Transitions and Kin Assistance in Old Age: a Cohort Comparison», David Van Tassel et Peter N. Stearns, eds., Old Age in a Bureaucratic Society..., 119-120.

24 LN, Recensement de 1861. Soit 40\% de celles qui étaient chez les Sœurs Grises et $57 \%$ de celles qui étaient chez les Sœurs de la Providence. 
et les blasphémateurs, étaient systématiquement éconduits ${ }^{25}$. Ceux qui restaient acceptaient, souhaitaient même l'atmosphère et les rites religieux inséparables de la vie dans ces établissements, des soins que les sœurs prodiguaient et du gîte qu'elles offraient ${ }^{26}$. Les protestants, les athées et même les catholiques plus tièdes ont pu trouver pénible un milieu de vie qui avait tout du couvent, où l'horaire imposé par la règle de la communauté rythmait la journée et où la religion et ses symboles coloraient l'atmosphère. Il faut jeter un coup d'œil sur ce qu'était la vie à l'intérieur de ces établissements pour mieux comprendre pourquoi des hommes et des femmes y sont demeurés jusqu'à leur mort, et pourquoi un nombre croissant d'entre eux y faisaient un court séjour, puis partaient.

\section{LA VIE ET LA MORT DANS LES ÉTABLISSEMENTS}

Les personnes âgées et malades des deux sexes, que soignaient les Sœurs de la Providence et les Sœurs Grises, faisaient partie d'un vaste réseau d'établissements dirigés par les religieuses, imbriqués de diverses manières dans les structures hiérarchiques de l'Église catholique et participant aux luttes de pouvoir qui s'y déroulaient. La règle de chaque communauté rythmait la vie quotidienne. L'année se déroulait sous le signe des fêtes et des célébrations religieuses, soulignées à l'occasion par des visites de dignitaires ecclésiastiques. Le catholicisme ultramontain et romantique de l'époque imprégnait l'atmosphère générale ${ }^{27}$. Dans chaque établissement, la personnalité des religieuses et de leurs auxiliaires, ainsi que les caractéristiques spirituelles, organisationnelles, rituelles et hiérarchiques de chaque congrégation déterminaient l'ambiance et l'état d'esprit qui y régnaient. En effet, comme Claude Langlois l'a noté dans son étude sur les congrégations françaises de la même époque, chacune avait son «esprit particulier $\aleph^{28}$. Même si les Sœurs Grises et les Sœurs de la Providence partageaient le même genre d'activité à caractère social (visiter les pauvres, donner asile aux orphelins, aux malades et aux personnes âgées, tenir des dispensaires pour les malades et organiser des soupes populaires pour les pauvres), les deux congrégations étaient très différentes, par leur histoire, leur personnalité collective et leurs tâches spécifiques.

25 ASGM, (F103-26/3) Table de la $2^{\mathrm{e}}$ partie du Coutumier. Petites règles. «Petits règlements», 137.

26 Les résidantes qui n'étaient pas catholiques comptaient pour moins de 1\%. Plusieurs se convertirent au catholicisme avant leur admission dans l'un ou l'autre des établissements; d'autres firent de même pendant leur séjour.

27 Lucien Lemieux, Histoire du catholicisme québécois, I: Les XVIIIe et XIXe siècles, 1: Les années difficiles (1760-1839) (Montréal, Boréal, 1989), 10.

28 Claude Langlois, Le catholicisme au féminin. Les congrégations françaises a supérieure générale au XIX'e siècle (Paris, Éditions du Cerf, 1984), 71. 
Les Sœurs Grises s'occupaient des pauvres et des vieillards à Montréal depuis que Marguerite de Lajemmerais d'Youville, devenue veuve, avait commencé à le faire, vers 1730 . Par la suite, elle-même et ses successeurs avaient reçu l'aide tant financière que spirituelle des Sulpiciens, développé leur expertise et établi leur tradition. Émilie Gamelin, était aussi veuve depuis peu quand elle a commencé à donner asile à des femmes âgées à la fin des années 1820 . La fondation officielle des Sœurs de la Providence en 1843 avait d'ailleurs été encouragée par Mgr Bourget ${ }^{29}$. Par moments, les deux congrégations furent des pions dans la lutte de pouvoir que se livraient le Séminaire et l'Évêché. Avec l'accroissement des désaccords entre ces derniers, les Sœurs de la Providence virent se réduire considérablement l'aide financière qu'elles recevaient des Sulpiciens, ce qui les força à chercher d'autres sources de revenus et d'épargne ${ }^{30}$. À cause de leurs difficultés financières chroniques et faisant de nécessité vertu, elles se vouèrent davantage que les Sœurs Grises à une vie de pauvreté où l'on s'en remet à la Providence. Ces difficultés financières ont marqué le travail quotidien des Sœurs de la Providence et, vraisemblablement, la vie de leurs pensionnaires, à un degré que l'on ne retrouve pas chez les Sœurs Grises.

Il est malaisé de brosser un tableau détaillé de la vie quotidienne des personnes âgées dans ces établissements. Le soin des vieillards n'était qu'une des raisons d'être de ces deux communautés, et les sœurs chargées de tenir les annales des différents hospices et de la maison mère étaient plus enclines à mentionner la présence de personnes âgées lors d'occasions spéciales qu'à évoquer leur vie de tous les jours. On en apprend plus sur leur vie spirituelle que sur les aspects matériels de leur vie quotidienne. Les souvenirs sélectifs et les descriptions des annalistes nous donnent cependant un aperçu de certains aspects de leur vie, de la manière dont les sœurs les considéraient et de leur rôle comme bénéficiaires de la charité.

Dans les deux communautés, les vieillards pauvres et malades logeaient dans des salles qui leur étaient assignées ou dans des dortoirs. Dans les dernières années du XIX ${ }^{e}$ siècle, les Sœurs Grises avaient au moins deux «salles des vieilles» à la maison mère, et au moins une pour les «vieux». En 1879, on trouvait dans les nouveaux

29 Denise Robillard, Émilie Tavernier-Gamelin (Montréal, Éditions du Méridien, 1988).

30 ASP, «Chroniques»; Huguette Lapointe-Roy signale que les Sœurs Grises reçurent des Sulpiciens des subventions près de vingt fois plus élevées que les Sœurs de la Providence, Charité, 36. La rivalité n'était pas seulement d'ordre financier: elle s'exprima à de nombreuses reprises relativement au territoire relevant de chaque congrégation ou encore à propos du moment où devaient avoir lieu les retraites. 
bâtiments de l'Hospice Saint-Joseph un dortoir pour les femmes âgées autonomes, une infirmerie pour les autres et une grande salle pour les hommes âgés, où l'on trouvait aussi un réfectoire, un dortoir et un fumoir ${ }^{31}$.

Chez les Sœurs de la. Providence, une section principale était réservée aux personnes âgées, les plus malades étant parfois logées dans des chambres à part. Le nombre de femmes soignées à l'Asile de la Providence augmenta régulièrement: à partir des sept ou huit «protégées» de Mère Gamelin qui y vivaient encore à la fondation de la congrégation en 1843, leur nombre passa à environ 100 durant les années 1860 et 1870 . Ce nombre passa rapidement à plus de cent à la fin des années 1880. À l'origine, elles n'admettaient que des femmes bien qu'après 1858 elles aient accepté un petit nombre d'hommes chaque année. L'Asile de la Providence conserva sa caractéristique d'établissement géré par des femmes, pour des femmes, contrairement à l'Hôpital Général: les Sceurs Grises, en effet, admettaient les hommes comme les femmes. Dans les années 1860 et 1870, elles donnèrent asile à plus de 200 hommes et femmes infirmes, leur nombre variant selon les places disponibles et divers facteurs extérieurs.

Une sœur, aidée occasionnellement par une consœur ou par une laïque, était en charge de chaque dortoir. Leur comportement envers les pauvres et les malades faisait l'objet d'instructions très précises. On exigeait des Sœurs Grises qu'elles traitent les pauvres avec patience, affection et abnégation, comme une mère l'aurait fait avec ses enfants. Il appartenait aux sœurs de vérifier si leurs pensionnaires avaient été baptisées et si elles avaient une connaissance satisfaisante du catéchisme, des prières de base et des sacrements. Dans le cas contraire, elles devaient entreprendre leur instruction religieuse sans attendre qu'elles soient à l'agonie, gardant bien présent à l'esprit que leur priorité était l'état spirituel de celles qui leur étaient confiées, particulièrement les pauvres ${ }^{32}$.

La maladie, l'épuisement, la mort ou de nouvelles obédiences entraînaient de fréquents changements des religieuses responsables. Leurs auxiliaires étaient souvent des hommes ou des femmes qui avaient souhaité devenir prêtres ou religieuses mais qui, n'ayant pas été admis, avaient choisi de consacrer leur vie à prendre soin des infirmes.

Les personnes âgées des deux sexes qui ne pouvaient plus se déplacer pouvaient demeurer dans ces salles et y recevoir la plupart

31 ASGM, CM, I: 485-486.

32 ASGM, «Petits règlements, Chap. IX. Règle des Hospitalières». 
des soins physiques et spirituels dont elles avaient besoin. On fut très heureux, à l'Asile de la Providence, lorsqu'en $1840 \mathrm{M}^{\mathrm{gr}}$ Bourget $\mathrm{y}$ autorisa la célébration de la messe quotidienne, plusieurs femmes âgées étant incapables de se rendre à l'église. Dans les années qui suivirent, on installa de petites chapelles, des autels et des oratoires où l'on disait la messe de temps en temps, dans les divers dortoirs des Sœurs Grises ${ }^{33}$.

Les résidantes n'étaient toutefois pas confinées à leur chambre, et celles qui le pouvaient se déplaçaient assez fréquemment pour diverses raisons, aussi bien religieuses que profanes. Après la fondation officielle de leur congrégation en 1843, les Sœurs de la Providence et la plupart de leurs pensionnaires âgées continuèrent d'assister à la grand-messe à la Cathédrale, située à deux pas de chez elles ${ }^{34}$. Dans les grandes occasions, les congés et particulièrement les jours de fête, les vieilles de chaque établissement pouvaient se joindre aux célébrations ou demeurer dans leurs chambres qui s'intégraient alors au parcours d'une longue procession passant dans les corridors de l'hospice. Ainsi, en octobre 1847, pour célébrer le $100^{\mathrm{e}}$ anniversaire de la présence des Sœurs Grises à l'Hôpital, on célébra de nombreuses messes à la suite desquelles les résidants pauvres furent autorisés à aller se promener en ville ${ }^{35}$.

Les célébrations religieuses allaient souvent de pair avec des célébrations à caractère plus profane. Ainsi, à l'Asile de la Providence, les fêtes des saints patrons de la mère supérieure, l'anniversaire de l'évêque ou le Jour de l'An étaient l'occasion de réjouissances auxquelles pouvaient se joindre toutes les résidantes aptes à se rendre à la salle de la communauté ${ }^{36}$. Toutefois, lors de ces événements, on eut de plus en plus tendance à reléguer les vieillards au second plan: leur âge, leur maladie, leur handicap, parfois même leur mauvaise odeur, leur confusion d'esprit ou leur caractère difficile n'en faisaient pas des objets de charité aussi attirants que les orphelins de plus en plus nombreux, qu'on habillait spécialement pour l'occasion et qui étaient «beaux comme les anges ${ }^{37}$ ».

Les personnes âgées demeuraient toutefois au cœur du travail des deux communautés. Les femmes âgées étaient la raison d'être des Sœurs de la Providence, le symbole même de leur fondation. Le

33 ASGM, «Ancien Journal 3», 242, 305.

34 APSP, «Chroniques», 19 avril 1840.

35 ASGM, «Ancien Journal 1», 519.

36 APSP, «Chroniques», août, 187; Ibid., 180, 394-395.

37 ASGM, M. Thibaud, avocat, parlant au dîner pour les vieilles, «Chroniques», $1876,22$. 
4 mars 1878, elles organisèrent une grande fête pour célébrer le «50ième anniversaire du jour où la Révérende Mère Gamelin prit des vieilles sous ses soins». La supérieure, Mère Caron, profita de l'occasion pour souligner l'importance des personnes âgées pour leur congrégation. «C'est à elles que nous devons, jusqu'à un certain point, notre vocation», rappela-t-elle, en soulignant que la communauté n'aurait pas existé «si elle n'avait pas eu de vieilles à soigner ${ }^{38}$.»

Il est difficile d'évaluer les soins que recevaient les résidantes, ou leur niveau de vie, par rapport à ce à quoi elles étaient habituées. Beaucoup ont assurément reçu de meilleurs soins qu'elles n'en auraient eus au dehors; certaines ont sans doute reçu les meilleurs soins de leur vie. Elles avaient la certitude d'avoir un lit, des repas, des vêtements et de pouvoir se laver au moins aussi souvent qu'on le faisait dans la société de l'époque. Lorsqu'une crise survenait en ville, surtout lors de l'épidémie de typhus de 1847, pendant laquelle beaucoup de sœurs des deux communautés travaillaient jour et nuit auprès des immigrants touchés par la maladie, le personnel soignant était rare. À l'Asile de la Providence, les Dames de Charité et les plus âgées des orphelines offrirent leur aide. Le fait que les sœurs semblent avoir réussi à empêcher la contagion de se répandre chez les malades et les vieillards, même à de tels moments d'épidémie, atteste de façon éloquente de la qualité de l'hygiène et des soins dans les deux communautés ${ }^{39}$.

Il ne faudrait pas croire que la vie dans ces établissements était toujours reposante et tranquille, ou encore isolée des événements et des dangers que présentait la vie au $\mathrm{XIX}^{\mathrm{e}}$ siècle. Le feu et les inondations bouleversaient la vie quotidienne d'un couvent ou d'un hospice comme ils le faisaient partout ailleurs. Lorsque les sœurs décidaient de faire déménager leurs vieillards dans d'autres résidences ou, comme ce fut le cas chez les Sœurs Grises, de déménager leur couvent tout entier dans une autre partie de la ville, on peut s'imaginer le tableau presque caricatural des résidants, appuyés sur des béquilles ou l'un sur l'autre, tenant à la main leurs biens personnels: «Toutes les vieilles capables de marcher, boiteuses, aveugles etc., se grimponnaient de leur mieux, ayant ou une chaise, ou un pot, une boîte qu'elles portaient dans leur salle actuelle ${ }^{40} . »$ Lors d'un autre déménagement, la plus grande joie d'un vieil aveugle fut de retrouver sa chaise et son «crachoir» dans son nouveau dortoir ${ }^{41}$.

38 APSP, «Chroniques», 1878, 198.

39 ASGM, «Ancien Journal, 1847», 507; APSP, «Chroniques, 1847».

40 APSP, «Chroniques», octobre 1846; ASGM, «Ancien Journal, 3», 1870, 197-220.

41 ASGM, CM 1, 438. 
Ce n'était pas non plus une vie de loisirs. Comme dans les établissements protestants, les résidants qui pouvaient le faire devaient travailler $^{42}$. On s'attendait des hommes qu'ils se livrent aux tâches compatibles avec leur état physique. Chez les Sœurs Grises, les femmes devaient faire leur lit et leur «petit ménage» chaque jour. Elles participaient aussi à la fabrication de divers objets religieux, dont la vente assurait par la suite des revenus, ou à la fabrication de vêtements, de literie, de couvertures et d'autres objets nécessaires à l'établissement ${ }^{43}$. Dans les premières années d'existence de l'Asile de la Providence, les femmes âgées aidaient les sœurs à faire la lessive pour l'Archevêché de Montréal, assurant ainsi des revenus à l'établissement. Lors de l'épidémie de choléra de 1854, certaines d'entre elles aidèrent les sœurs à prendre soin des petits enfants. Bien que l'on n'en trouve nulle part confirmation, il est possible que certaines autres aient aidé les sœurs à fabriquer leur controversé «Sirop de Gomme d'Épinette», des reliquaires, des statues de cire de l'Enfant-Jésus, des soutanes, des habits mortuaires et des chaussures, qui constituaient les principaux biens produits par la communauté pour gagner l'argent nécessaire à son existence ${ }^{44}$.

Il est possible que certains résidants, frustrés par de telles obligations, aient simulé la maladie pour ne pas avoir à travailler. Il semble que d'autres l'aient fait volontiers, par souci de participer au bien-être matériel ou spirituel de leur foyer. En 1865, les vieilles de l'Hôpital Général offrirent de faire du travail supplémentaire afin de faciliter l'achat d'«un corps saint», que Mgr Bourget s'était proposé d'acquérir pour la maison mère ${ }^{45}$.

En guise de paiement pour le gîte et les soins qu'on leur prodiguait, ces hommes et ces femmes devaient contribuer par leur travail au fonctionnement quotidien de l'établissement. Ils devaient y assurer une propreté minimum, et on attendait d'eux une certaine participation à sa vie religieuse. Cette participation comportait les pratiques ordinaires du catholicisme, comme la messe, la prière à des moments précis de la journée et l'assistance aux retraites. Les Sœurs Grises qui s'occupaient des vieilles malades avaient pour consigne de s'assurer que leurs patientes s'acquittent de leurs devoirs religieux: qu'elles «entendent la Sainte Messe avec attention et piété aux jours d'obligation, autant que leur état d'infirmité le leur permettra... entendre la

42 ASGM, «Petits Règlements», article II.

43 Huguette Lapointe-Roy, Charité, 190-191.

44 APSP, «Chroniques», 1828-1884. Leur production de sirop de gomme d'épinette leur valut un procès au début des années 1870 . Elles finirent par avoir gain de cause, mais le litige affecta beaucoup la communauté.

45 ASGM, «Chroniques, 2», 1867, 16; 1865, 253. 
Sainte Messe tous les jours», qu'elles observent les jours de jeûne et se confessent ${ }^{46}$. Cet encadrement religieux offrait assurément réconfort spirituel et satisfaction aux catholiques pieux, en leur donnant le sentiment de participer à leur propre salut comme au bien de l'établissement. Le fait de prier ensemble pour qu'une consœur reprenne conscience et puisse se confesser et recevoir les derniers sacrements, ou encore pour qu'il pleuve lors d'une sécheresse estivale ou, enfin, pour qu'un peu de beurre vienne agrémenter leur modeste repas, renforçait la solidarité spirituelle et sociale entre les résidantes ${ }^{47}$.

Les prières, les statues de saints et les reliques, ainsi que les divers rites de l'Église imprégnaient la vie quotidienne des résidantes de la riche et symbolique atmosphère du catholicisme ultramontain et romantique du XIX $\mathrm{X}^{\mathrm{e}}$ siècle. Cela n'empêchait pas cependant qu'il y eût aussi de la place pour des distractions plus mondaines. Le plus grand plaisir des vieux logés dans les nouveaux bâtiments de l'Hospice Saint-Charles après 1880 était leur fumoir où «on fume le matin, le midi, le soir. Un brouillard épais tourbillonne dans cet appartement, à peine peut-on reconnaître les voisins qui partagent le même siège ${ }^{48}$.» Dans les grandes occasions, les hommes sortaient leurs violons et les vieux pouvaient danser et chanter quelque temps. Il leur arrivait même d'aller à la campagne pour la journée.

Les pensionnaires âgés ont aussi joué un autre rôle, qui a pu en indisposer quelques-uns. Bénéficiaires de la charité, ils en étaient aussi la personnification et le symbole, bien différemment toutefois de ce que pouvaient représenter les orphelins. C'était de cette manière qu'on les présentait lorsque des dignitaires rendaient visite aux sœurs. Cela jouait à leur avantage, comme à leur désavantage. Les sœurs qui rédigeaient les chroniques utilisaient couramment des pronoms possessifs pour parler avec affection de l'ensemble de ces personnes âgées et de ces infirmes. Elles deviennent ainsi «nos vieilles», parfois «nos chères vieilles» ou «chers vieillards», «nos bonnes vieilles» ou «nos vieilles infirmes ${ }^{49} \gg$. Néanmoins, on souligne aussi maintes et maintes fois leurs infirmités, leur laideur et leur mauvaise odeur. Ceci peut s'expliquer d'au moins trois manières: premièrement, il est possible que certaines d'entre elles aient été vraiment répugnantes; deuxièmement, plus elles inspiraient le dégoût, plus l'acte de charité était méritoire et plus le laïc ou la religieuse en pouvait attendre un bénéfice spirituel;

46 ASGM, «Petits règlements», 132-133.

47 APSP, «Chroniques», 1845, décembre 1871.

48 ASGM, CM-1, 487.

49 Voir, par exemple, APSP, «Chroniques», 10 janvier 1850; 28 juillet 1854; 1883, 31, 86; ASGM, «Circulaire Mensuelle», 4, 6. 
enfin, un dernier élément qui différenciait radicalement les vieux des orphelins «beaux comme les anges», vient du lien qu'on établissait inévitablement entre leurs infirmités et leur âge et la mort qui approchait. En 1878, au cours d'un dîner que les Messieurs de la Société Saint-Vincent-de-Paul donnaient pour quatre-vingts infirmes âgés vivant à l'Hospice Saint-Charles des Sœurs Grises, l'évêque eut des propos sans équivoque à leur endroit, leur parlant de la mort qui approchait et leur soulignant l'importance de pouvoir mourir en paix, après avoir lutté contre les souffrances de la vie ${ }^{50}$. Dans le discours de la charité, ces hommes et ces femmes symbolisaient l'inéluctabilité de la mort et rappelaient le devoir de chacun de s'y préparer. C'était un moyen puissant dans l'argumentaire d'une Église qui cherchait à imposer son hégémonie dans un monde en mutations rapides et dans une ville en partie protestante.

Les vieux qui trouvaient insupportables leur travail, leurs obligations religieuses ou leur rôle de symbole de la charité avaient diverses options. Ils pouvaient se soustraire à quelques-unes de leurs responsabilités en exagérant leurs infirmités. Ils pouvaient se conformer extérieurement tout en gardant pour eux leur état d'esprit. Ils pouvaient aussi tout simplement partir. Leur décision dépendait probablement beaucoup moins de leur désir que des solutions de rechange qui les attendaient à l'extérieur. Toutefois, quand leur mauvaise volonté était trop évidente, on pouvait leur demander de partir. À ce propos, les chroniques et les registres mentionnent à quelques reprises le fait que quelqu'un «ne sympathisait pas ${ }^{51} »$.

Au cours du siècle, les départs volontaires eurent tendance à augmenter: alors que dans les années 1840 et 1850 , la proportion de veuves qui partaient était de une sur cinq chez les Sœurs Grises et de une sur dix chez les Sœurs de la Providence, elle passe au tiers entre les années 1870 et 1890 . Certaines d'entre elles - il est difficile d'en évaluer le nombre - quittaient parce qu'elles ne pouvaient plus endurer certains aspects de la vie de l'établissement; d'autres étaient entrées pour une raison précise, la maladie ou l'absence temporaire d'un membre de la famille qui s'occupait d'elles; enfin, un petit nombre des veuves des Sœurs de la Providence furent transférées dans d'autres établissements de la communauté. Mais après 1870, pour la plupart de celles qui quittaient, on trouve dans les registres la mention «sortie d'elle même». Certaines d'entres elles retournèrent vivre dans leur famille, et une seule, semble-t-il, s'est remariée. Quelques-unes, enfin, quittèrent mais finirent par revenir.

50 ASGM, «Circulaire Mensuelle», mars 1878, 92-93.

51 Huguette Lapointe-Roy, Charité bien ordonnée, 187; «Petits règlements», 134. 
On entrait et on sortait de ces établissements pour différentes raisons sur lesquelles on ne peut avoir qu'une idée générale. Certains ont pu trouver insupportable le rigorisme croissant du catholicisme ultramontain du XIX ${ }^{\mathrm{e}}$ siècle. D'autres ont pu être froissés d'être considérés comme des objets de la charité, malgré les soins et le gîte qu'on leur accordait. D'autres, enfin, ont pu être si bien soignés qu'ils aient pu retourner dans leur famille ou chez des amis. Des historiens prétendent que l'industrialisation a privé les familles des moyens de prendre soin de leurs vieux. Toutefois, l'expansion du travail salarié et les contingences qu'imposait le travail aux familles permettaient, dans un sens, aux proches parents âgés en bonne santé de remplir de nouveaux rôles: ils pouvaient, par exemple, veiller sur les enfants lorsque la mère était au travail ou au magasin. Dans les familles où plusieurs adultes exerçaient des métiers, les revenus pouvaient faire vivre une tante célibataire ou un parent veuf. L'expansion industrielle et la multiplication des emplois ont permis à leur famille de les faire vivre plus facilement ${ }^{52}$.

\section{MOURIR DANS UN ÉTABLISSEMENT}

La mort en institution demeurait cependant le sort de la majorité des résidants (tableau 2). Même pour ceux qui quittaient, la mort n'était jamais bien loin. Dans le Montréal du XIX ${ }^{\mathrm{e}}$ siècle, où le taux de mortalité, tous âges confondus, était plus élevé que dans la plupart des autres villes d'Amérique du Nord, la vie et la mort se fondaient l'une dans l'autre ${ }^{53}$; elles n'étaient pas, non plus, vraiment distinctes dans une foi où la préoccupation de la mort constituait une partie essentielle de la théologie. L'agonie et la mort étaient toujours présentes dans les dévotions et les activités quotidiennes des vieux et des infirmes vivant en institution. Lors de «veillées», ils priaient avec leur compagnon agonisant et faisaient de même auprès de sa dépouille mortelle. Ils priaient aussi pour les sœurs agonisantes et décédées, assistaient à leurs funérailles et étaient tenus de prendre place à côté de leur dépouille mortelle exposée dans l'église ${ }^{54}$.

52 Les nouvelles possibilités de travail permirent aux veuves qui vivaient chez elles avec leurs enfants de les garder à la maison une fois devenus adultes plus longtemps que les familles dont les deux parents étaient en vie. À ce propos, voir Bettina Bradbury, «Surving as a Widow in Nineteeth Century Montreal», Urban History Review/Revue d' histoire urbaine, 17,3 (février 1989): 152-153; Lorna R. McLean, «Single Again: Widow's Work in the Urban Family Economy, Ottawa, 1871», Ontario History, 83,2 (juin 1991): 134-137.

53 Jean-Claude Robert, «The City of Wealth and Death: Urban Mortality in Montreal, 1821-1871», Wendy Mitchison et Janice Dickin McGinnis, eds., Essays in the History of Canadian Medecine (Toronto, McClelland and Stewart, 1988), 18-38.

54 «Petits règlements», 31 et les chroniques de chaque institution. 
Tableau 2

Proportion des veuves mortes à l'Hôpital Général et à l'Asile de la Providence, 1830-1891

\begin{tabular}{|c|c|c|c|c|c|c|c|}
\hline \multicolumn{8}{|c|}{ Asile des pauvres à l'Hôpital Général } \\
\hline & & Nombre de & \multicolumn{2}{|c|}{ Décès } & \multicolumn{2}{|c|}{ Départ } & \multirow[t]{4}{*}{ Indéfini } \\
\hline & & & Nombre & & Nombre & & \\
\hline $1830-1849$ & & 46 & & 78 & 10 & 22 & \\
\hline $1850-1869$ & & 100 & 55 & 55 & 45 & 45 & \\
\hline $1870-1890$ & & 188 & 108 & 57 & 73 & 39 & 7 \\
\hline \multicolumn{8}{|c|}{ Asile de la Providence } \\
\hline & $\begin{array}{l}\text { Âge moyen à } \\
\text { l'admission }\end{array}$ & & & & & & \\
\hline $1830-1849$ & 74 & 70 & 57 & 81 & 7 & 10 & 5 \\
\hline $1850-1869$ & 68 & 57 & 39 & 68 & 7 & 12 & 10 \\
\hline $1870-1887$ & 71 & 90 & 61 & 68 & 29 & 32 & \\
\hline
\end{tabular}

Sources: $\quad$ ASGM, Registre d'admission des pauvres, vol. II, 1797-1854 (G6/IR3); Registre des pauvres et des orphelins, vol. III, 1854-1890 (G6/IR5); APSP, Registre des femmes vieilles et infirmes de l'Asile de la Providence, Montréal, depuis 1830 (1830-1891). 
Dans les années 1830 et 1840 , plus des trois quarts des veuves qui habitaient dans les maisons des deux communautés y finissaient leurs jours. Dans les décennies qui suivirent, cette proportion se réduisit environ aux trois cinquièmes. Comme les autres pensionnaires, la majorité des veuves continuaient à mourir dans ces asiles, avec les secours de la religion que leur prodiguaient quotidiennement les sœurs, leurs aumôniers et les prêtres visiteurs. Elles pouvaient «y mourir chrétiennement», évitant ainsi les obstacles à une bonne mort qu'elles auraient rencontrés dans une institution protestante et que Mgr Bourget décrivait soigneusement dans une lettre pastorale publiée en avril 1876. «Rien [...] de plus nécessaire et de plus désirable qu'une bonne mort, comme aussi rien de plus terrible qu'une mauvaise mort, la mort dans le péché.» Ce genre d'admonition incitait à finir ses jours dans un hospice catholique et donnait à l'Église un puissant moyen de contrôle spirituel.

Les religieuses n'avaient cependant qu'un rôle d'auxiliaires dans la préparation à une bonne mort. Elles pouvaient disposer les malades à mourir, les encourageant à endurer leurs souffrances patiemment et à «bien régler toute leur vie», et même à les ramener à l'Église catholique si cela se révélait nécessaire ${ }^{55}$. Toutefois, seuls les prêtres pouvaient entendre les confessions, porter le Saint-Viatique et administrer l'extrême-onction. $\mathrm{M}^{\mathrm{gr}}$ Bourget avait insisté sur l'importance pour le malade d'être en pleine connaissance lorsqu'on lui administrait ces sacrements, afin d'éviter «les illusions des démons qui cherchent à les tromper, pour les empêcher de jouir d'un si grand bienfait et d'une grâce si nécessaire ${ }^{56}$ ». Les sentiments de culpabilité ressentis par les Sœurs de la Providence lorsque Delphine Thoin mourut sans avoir repris conscience, et la description détaillée de la situation qu'elles font dans leur chronique, mettent en relief l'importance qu'elles attachaient à ce que leurs «chères vieilles» fassent une bonne mort et le fait qu'elles y parvenaient généralement. À cet égard, elles eurent tout lieu de se réjouir lorsque Josephte Simard, une veuve qui avait séjourné quatre ans dans la salle des vieilles, mourut en 1871, à l'âge de 76 ans. Mais, son histoire fait aussi allusion aux

55 «Lettre pastorale de Mgr Bourget», 26 avril 1876, Mandements, 7: 318. Les sœurs qui s'occupaient quotidiennement des vieillards pouvaient effectuer ce travail de préparation; c'était aussi la tâche des aumoniers de chaque institution. Lors des retraites, il n'y eut pas de conversion parmi les pauvres vivant chez les Sœurs Grises, puisqu'ils étaient déjà «... véritablement les enfants chéris du bon Dieu par les bons soins de leur infatigable et si zélé aumonier». ASGM, "Circulaire mensuelle», 1877, 37. Voir également dans Serge Gagnon, Mourir hier et aujourd' hui (Québec, Presses de l'Université Laval, 1987), 27-34.

56 Mandements, 1876, 321-318. Sur la curiosité que suscitaient les démons et les esprits à cette époque, et sur l'attitude de l'Église à ce propos, voir Sylvain et Voisine, Histoire du Catholicisme, 85. 
problèmes que pouvait occasionner aux sœurs la dépendance à l'égard d'un prêtre pour administrer les derniers sacrements. À son admission en institution, en 1867, Josephte avait déjà ses facultés amoindries en raison de son âge; elle réussit pourtant à faire ses Pâques jusqu'en 1870. À l'automne, sentant que son mal s'aggravait, elle demanda à voir un prêtre. La sœur hospitalière eut beaucoup de difficultés à persuader l'aumônier de rendre visite à la vieille dame qui, d'après lui, n'avait déjà plus toute sa tête ${ }^{57}$. Il se laissa toutefois convaincre et elle se «confessa très bien. Elle reçut l'absolution, puis elle tomba tout à fait en enfance.» Les sœurs se réjouirent qu'elle ait su choisir un moment de lucidité pour se confesser et recevoir l'absolution même si, pour l'extrême-onction, on la décrivait comme «délirante au point de faire rire les plus sérieux ${ }^{58}$ ».

\section{LES LIENS AVEC LA VILLE: LES VISITEURS, LA CHARITÉ ET LA MORT}

La plupart des vieux et des mourants dont prenaient soin les Sœurs Grises et les Sœurs de la Providence habitaient dans des parties de leurs couvents ou dans des immeubles imposants, qui pouvaient donner l'impression d'être isolés du reste de la ville. Cependant, les vieux, les religieuses qui les soignaient et les autres pensionnaires n'étaient, ni dans la vie, ni dans la mort, véritablement coupés du monde urbain qui les entourait. Dans cette dernière section, je voudrais me concentrer sur le genre de liens unissant les communautés et leurs pensionnaires au reste de la société urbaine, dont ils faisaient partie tout en en étant séparés. Je m'intéresserai d'abord à ceux qui visitaient ces communautés, ensuite aux campagnes de financement et à d'autres initiatives caritatives, pour finalement examiner de quelle manière la mort, la crainte de faire une mauvaise mort et les idées au sujet du purgatoire et de l'enfer, ont créé des liens spirituels et économiques entre les sœurs, les vieux et la population laïque montréalaise.

Les visiteurs permettaient aux sœurs et aux résidants un contact partiel avec les informations et quelques-unes des personnalités, principalement catholiques, de l'époque. Chez les Sœurs Grises, les résidants pouvaient avoir des nouvelles de ce qui se passait dans leur famille ou dans leur voisinage, par des amis ou des proches, autorisés à les voir sans permission spéciale de la mère supérieure, ce qui n'était

57 Sylvain et Voisine signalent qu'une des principales causes de plaintes à l'endroit du clergé concernait les prêtres qui négligeaient leurs devoirs envers les mourants. L'histoire $d u$ catholicisme, 2: 342 .

58 APSP, «2 ${ }^{\circ}$ volume des chroniques», décembre 1867; Registre des vieilles, 29 septembre 1867. 


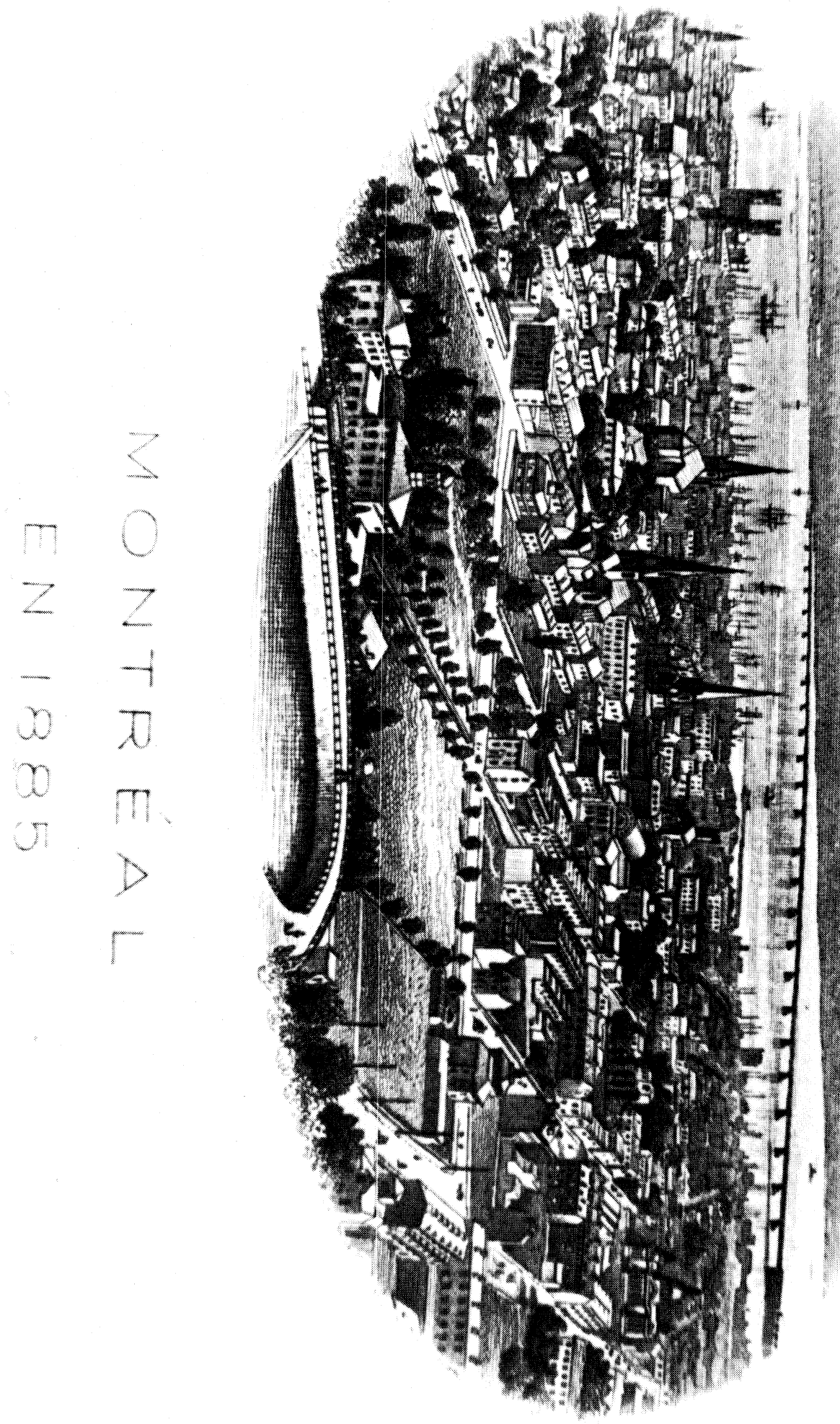


pas le cas pour les autres visiteurs ${ }^{59}$. Pareillement, les visites de membres du clergé ne se limitaient pas au prêtre desservant la communauté ou à l'aumônier de l'asile. Outre les prêtres qui venaient régulièrement dire la messe, entendre les confessions et s'acquitter de toutes les autres tâches de nature spirituelle que les sœurs ne pouvaient effectuer, les asiles recevaient la visite de membres du clergé de passage, d'évêques et d'autres dignitaires de l'Église. Ils visitaient systématiquement les vieux et les malades dans leurs chambres, les saluaient chaleureusement lorsqu'ils s'alignaient pour les accueillir, s'arrêtaient parfois pour leur parler et disaient quelquefois la messe pour eux. Mgr Bourget rendait assez fréquemment ce genre de visites, particulièrement chez les Sœurs de la Providence, qu'il considérait comme son œuvre et qu'il dirigeait en patriarche. Lors de la plupart de ces visites, il consacrait du temps aux femmes âgées et leur donnait parfois la communion dans leur salle ${ }^{60}$.

À cette époque l'influence de Rome se faisait de plus en plus sentir sur l'Église du Québec: le dogme de l'infaillibilité pontificale venait d'être proclamé et avait reçu bon accueil, développant un véritable «culte du pape». Dans ce contexte, la visite d'un délégué apostolique était un événement d'une rare importance pour les sœurs et, sans doute, pour les plus religieux de leurs vieux ${ }^{61}$. Ces hommes, qui avaient vraiment vu le Pape et lui avaient parlé, pouvaient leur apporter des nouvelles directement du Vatican. Envoyé au Canada en 1877 comme délégué apostolique, en partie pour résoudre certains problèmes de l'Église du Québec, Mgr Conroy a sans doute été heureux de passer quelque temps dans l'atmosphère relativement calme de ces communautés ${ }^{62}$. Il visita les Sœurs Grises à au moins deux reprises. Les vieux, «les uns, inclinés sur leur bâton, les autres, se soutenant avec l'aide d'un compagnon moins infirme, quelques-uns aveugles, d'autres bien déformés», faisaient partie de la délégation qui l'accueillit et avec qui il conversa, leur donnant sa Croix pectorale à vénérer, ou son anneau, ou une bénédiction spéciale. Il rendit une visite analogue aux Sœurs de la Providence. Là aussi il accorda une attention spéciale aux vieilles,

touché de leurs misères... Il leur parla avec beaucoup de sympathie et sembla leur porter un bien vif intérêt. Cinq de ces

59 «Petits règlements», 148.

60 Voir, par exemple, APSP, «Chroniques», 1843; janvier 1869; juin 1871; avril 1868; ASGM, «Ancien Journal», II: 105-106; «Ancien Journal», III: 143.

61 Sylvain et Voisine, Histoire du Catholicisme, 2: 41, 73, 203.

62 Roberto Perrin, Rome in Canada. The Vatican and Canadian Affairs in the Late Victorian Age (Toronto, University of Toronto Press, 1990), 73-77, 223-225. 
pauvres infortunées étant retenues au lit par la maladie, le Délégué alla près de chacune et leur adressa quelques paroles de consolations, après quoi, il se retira en donnant la bénédiction papale $^{63}$.

Six ans plus tard, la visite du délégué apostolique Smeulders donna lieu à des scènes semblables.

On le vit s'approcher de chacunes d'elles, leur adresser de bonnes et saintes paroles, les exhorter à la patience, à la charité mutuelle et à la reconnaissance envers les sœurs qui leur prodiguent des soins assidus. La visite de Léon XIII lui-même n'aurait pas causé plus d'émotion à ces chères vieilles, tant elles se sentaient pénétrées de respect et d'amour envers son digne Représentant ${ }^{64}$.

Ces visites fréquentes de membres du clergé et de la hiérarchie de l'Église mirent en contact les résidants des établissements des deux communautés avec le monde religieux extérieur, contribuant à affermir leurs croyances. Les liens qui les unissaient aux laïcs de Montréal étaient d'un autre ordre, et la plupart du temps indirects. Beaucoup des fonds recueillis par les Sœurs de la Providence étaient destinés aux vieux et aux malades, mais ces derniers ne participaient pas directement à ces campagnes. C'étaient les Dames de la Charité qui travaillaient avec les sœurs et organisaient des bazars qui rapportaient chaque année environ $1000 \$$, dont la plus grande partie était destinée aux vieux. Les Sœurs de la Providence organisaient aussi des collectes dans les églises de Montréal, faisaient appel à des gens connus pour leur générosité et allaient jusqu'à quêter dans les marchés ou dans la rue (une pratique qui les rebutait) y rencontrant des gens qui pouvaient être sympathiques, indifférents ou parfois hostiles. Les personnes âgées des deux sexes ont certainement bénéficié des aliments et des vêtements que cette méthode de collecte permettait d'acheter. Ils partageaient aussi les dons en nature que faisaient des commerçants ou des marchands locaux: de la nourriture qu'on déposait à la porte de l'Asile de la Providence, du pain qu'on leur cédait sur les instances pressantes d'une religieuse, ou encore les aliments et les cadeaux qu'on leur offrait chaque année à Noël. La ferveur religieuse beaucoup plus que l'argent avait servi de base à la fondation de cette communauté qui dépendait pour son existence des dons de Montréalais bienveillants. Lorsque Mgr Conroy, le délégué apostolique, lui demanda en 1877 comment il faisait pour venir en aide à tant de gens avec de si maigres ressources, Mgr Bourget passa sous silence tous les

63 APSP, «Chroniques», 1877, 133.

64 APSP, «Chroniques», 1883, 175. 
efforts déployés par les sœurs pour permettre à leur communauté de se maintenir: «J'ai abandonné et confié cette communauté aux soins de la Providence de Dieu. Je n'ai eu nul autre secret ${ }^{65}$.»

Les dîners, qu'on donnait au moins une fois l'an pour les pauvres de chaque établissement, étaient l'une des seules occasions qui rassemblaient les trois groupes d'acteurs dans ce réseau de charité: les vieux et les malades, les religieuses et leurs bienfaiteurs montréalais. À l'Hôpital Général des Sœurs Grises, c'était les Messieurs de la Société Saint-Vincent-de-Paul qui organisaient ces dîners, appelés d'abord «soupers des pauvres» et rebaptisés ensuite «festin des pauvres». Infirmes, orphelins et aveugles, tous y étaient conviés ${ }^{66}$. Les «dîners des vieilles», organisés à l'Asile de la Providence, semblent ne s'être adressés qu'aux femmes âgées et, en raison des différences existant entre les deux congrégations, avoir été beaucoup plus modestes. La plupart du temps, d'autres femmes les organisaient: les Dames de Charité, dont le rôle a été beaucoup plus important que chez les Sœurs Grises, prirent d'abord l'initiative de ces dîners; occasionnellement, les sœurs elles-mêmes les organisaient; enfin, ils furent parfois dus à l'initiative de Montréalaises comme Luce Cuvillier, qui présida à plusieurs de ces dîners au début des années 1880 .

Il vaut la peine d'examiner de plus près le déroulement de ces dîners pour essayer d'en dégager la symbolique et le genre de relations qui y existaient. En janvier 1867, les Associés de Saint-Vincent-dePaul organisèrent un dîner à la maison mère des Sœurs Grises regroupant plus d'une centaine de personnes, apparemment toutes très désireuses de servir les pauvres. Il commença peu après dix-sept heures par la bénédiction de Mgr Bourget qui commença à servir la dinde qu'on avait préalablement découpée.

Malgré tous les préparatifs faits d'avance, et le service très prompt des Messieurs, le souper dura près d'une heure, ce n'était pas trop pour les gourmets d'hier soir, leur grand âge, leurs infirmités, rendirent un peu lents leurs mouvements, leurs yeux peut-être faisaient plus de feu que tout le reste. Les plus infirmes emboîtés dans de vastes chaises ne furent pas oubliés, on se portait vers eux avec la plus aimable complaisance...

Après le souper, Monseigneur dit les grâces, et les Messieurs se retirèrent avec les bénédictions et les remerciements des pauvres. On les introduisit à la salle de la Communauté, à la châsse de notre Vénérable Fondatrice. Sa Grandeur leur adressa quelques

66 ASGM, «Ancien Journal», III: 1, 120, 225, 340, 447. 
félicitations, et tous sortirent avec la paix et le bonheur que laisse après soi une bonne action ${ }^{67}$.

Les messieurs, «affublés d'un tablier blanc», se pressaient aux tables, les uns distribuant les assiettes, les autres y versant de la sauce. D'autres, «chargés d'énormes pots de thé bien sucré et bien chaud», en versaient «avec bonheur dans les coupes des conviés». On distribua ensuite aux vieux d' «énormes beignes» et des pommes, et l'on gratifia les orphelins de toute sorte de friandises. Dans la description qu'elle fit de l'événement, la sœur qui rédigeait la chronique mit l'accent sur l'attitude de «deux gentilshommes qui s'emparant de l'écuelle de deux de nos infirmes les plus dégoûtants, les firent manger à la cuillère avec une politesse et une bonté charmantes. Que la charité est donc bienfaisante puisqu'elle fait triompher des plus fortes répugnances de la nature ${ }^{68} . »$

Que nous apprennent ces rencontres cérémonielles entre les bénéficiaires de la charité et leurs bienfaiteurs? Les messieurs de la Société Saint-Vincent-de-Paul avaient certes d'autres occasions de côtoyer les pauvres de la ville, notamment lors de visites à domicile. Chacun, dans ce cas, gardait son rang. Ici, ces laïcs serviteurs des pauvres, ravalant leur dédain au point de faire manger les plus répugnants des vieux, donnent au contraire l'impression de s'adonner à une sorte de renversement ritualisé dess rôles de classe comme de sexe. Ils ne se contentent pas, en effet, de servir les pauvres comme faisait Jésus, mais ils le font vêtus comme des servantes, arborant souvent un tablier blanc semblable à celui des domestiques. Au surplus, les qualités qu'ils démontrent - la patience, la politesse et une bonté charmante - sont celles qu'on attribue généralement aux femmes. La religieuse qui rédige la chronique présume, sans doute à juste titre, que ces hommes sont repartis avec au cœur la paix et le sentiment de bonté que procure l'exercice de la charité. Cette transgression temporaire des principales frontières sociales - la classe et le sexe - a-t-elle accru leurs mérites? Il semble que ceux qui faisaient ces beaux gestes par charité y aient vu une magnifique occasion de faire fructifier leurs acquis spirituels, tout en affichant publiquement la noblesse de leur caractère.

Les dîners pour les vieilles à l'Asile de la Providence étaient empreints de beaucoup plus de simplicité. Ces dîners, où l'on voyait rarement beaucoup d'hommes, étaient généralement plus petits: d'une part parce qu'ils s'adressaient à un moins grand nombre de résidants

67 ASGM, Ibid., 1-3.

68 Ibid. 
et, d'autre part, parce qu'ils faisaient l'objet de moins de publicité. Le premier dîner qu'on rapporte fut organisé en 1850 par «quelques dames de Charité» qui servirent le dîner et rejoignirent ensuite les vieilles en "congé». À d'autres occasions, c'étaient les sœurs ellesmêmes qui organisaient les dîners, avec parfois l'aide de membres de leur famille. Luce Cuvillier, une bienfaitrice de la communauté, mieux connue des historiens comme la maîtresse de George-Étienne Cartier, organisa au moins trois dîners pour les femmes entre 1869 et 1884 . Une atmosphère beaucoup moins formelle que chez les Sœurs Grises régnait lors de ces dîners, comme en témoigne la description qui en fut faite en 1884: «La charitable Demoiselle y assiste et en fait les honneurs aidée de sept sœurs de communauté qui se trouvent réunies par hasard. Après le dîner, Mlle Cuvillier s'assied au milieu de ses bonnes vieilles, leur fit raconter des histoires pendant qu'elle leur distribue, elle-même, du tabac ${ }^{69} . »$

Si ceux qui participaient à ces dîners, donnaient aux pauvres ou faisaient la charité de toute autre manière espéraient que leurs bonnes œuvres leur permettraient d'aller au ciel, d'autres donnaient spécifiquement pour abréger les peines du purgatoire. Des visions de l'enfer, du purgatoire et des âmes des damnés dominaient en effet le discours religieux de l'époque. Il n'est pas étonnant, dans ces conditions, que plusieurs Montréalais aient cherché à accroître le nombre de personnes priant pour les âmes de leurs chers disparus afin de raccourcir leur séjour au purgatoire, si elles y étaient. L'Église conseillait depuis longtemps à ceux qui faisaient leur testament de demander des messes et des dons à cette intention. À Montréal, les plus fortunés donnaient leurs bijoux et leur argent, et faisaient aux sœurs des legs testamentaires pour qu'elles prient pour le repos de l'âme de leur conjoint décédé, pour eux-mêmes ou, plus globalement, pour les membres décédés de leur famille ${ }^{70}$. Il semble que cette pratique ait été particulièrement profitable aux Sœurs Grises. Dans l'ensemble, les prières pour les défunts, les veilles auprès des mourants et les dons de charité créèrent entre les vivants, les mourants et les morts de Montréal, laïcs comme religieuses, un réseau complexe

69 On parle de ces dîners dans les chroniques suivantes: ASGM, «Chroniques», 1850, 1856; 1858; 13 décembre 1869; 1876, 21; 1881, 14; 1883, 86; 1884, 258. Sur Luce Cuvillier, voir Brian Young, George-Etienne Cartier. Montreal Bourgeois (Montréal, McGill-Queen's University Press, 1981), 34-38. Elle était présidente des Dames de Charité de l'Asile de la Providence, au début des années 1860. APSP, «Chroniques», octobre 1862; novembre 1864.

70 Sylvain et Voisine, op. cit., 21, 307; Rousseau, op. cit., 161-163; sur les scurs à qui on demandait de prier pour des membres de la famille, voir ASGM, «Circulaire Mensuelle», I: 258; II: 312, 382, 426; Marie-Aimée Cliche, «L'évolution des clauses traditionnelles dans les testaments», 367. 
de relations économiques et spirituelles qui s'étendait bien au-delà des murs des couvents et des hospices.

\section{CONCLUSION}

Toutes les parties engagées dans le réseau de relations sociales et spirituelles de la charité en tiraient des bénéfices et y jouaient des rôles différents. Les communautés recevaient un appui financier et matériel, qui variait du simple don d'aliments aux riches legs testamentaires. Les gens profitaient des prières des religieuses et jouissaient de la satisfaction et du mérite que procure le fait de donner. La relation était réciproque. L'aumônier des Sœurs de la Providence le dit d'ailleurs sans ambages en 1876: «Si le monde a besoin des prières de la Communauté, celle-ci ne peut, en revanche, continuer de prier sans les aumônes des mieux nantis ${ }^{71}$.»

Les Sœurs de la Providence et les Sœurs Grises ont pu, avec l'argent qu'elles recueillaient ou qu'on leur donnait, sans compter ce que leur accordaient le gouvernement et les Sulpiciens, mettre sur pied une multitude d'œuvres sociales durables au nombre desquelles on compte les asiles où des centaines de personnes âgées et malades des deux sexes passèrent les dernières années de leur vie. Ces hospices offraient le gîte, le couvert et les soins médicaux aux personnes âgées ou infirmes qui n'avaient plus de famille ou étaient trop démunies pour se payer les soins dont elles avaient besoin. Ils étaient une ressource d'appoint inestimable pour les familles ouvrières incapables de prodiguer des soins adéquats à un parent vieillissant, veuf ou célibataire $^{72}$. Le nombre anormalement élevé de femmes seules et laïques qui moururent dans ces asiles au XIX ${ }^{\mathrm{e}}$ siècle, auxquels correspondent nos centres d'accueil contemporains, révèle le rôle essentiel que jouait la famille, principalement les enfants, comme soutien des personnes âgées dans les années précédant l'intervention de l'État dans le domaine de la sécurité sociale.

Peut-être Faure a-t-il raison lorsqu'il affirme que ces institutions ont pu être pour certaines personnes beaucoup plus un lieu de libération plutôt que de détention, c'est-à-dire un endroit où elles pouvaient prendre une sorte de revanche pour des années de travail ou

71 APSP, «Continuation des Chroniques», 1876, 24.

72 Peter Mandler, «Poverty and Charity in the Nineteenth-Century Metropolis: an Introduction", Peter Mandler ed., The Uses of Charity. The Poor on Relief in the NineteenthCentury Metropolis (Philadelphia, University of Pennsylvania Press, 1990), 12. L'auteur avance, à juste titre selon moi, que les historiens n'ont pas accordé assez d'importance à la charité comme élément d'une stratégie de survie de la classe ouvrière. 
de misère ${ }^{73}$. D'autres les ont sûrement considérés comme un havre de paix où les sœurs et l'environnement spirituel enrichissaient leurs derniers jours tandis qu'ils se préparaient pour la vie après la mort ${ }^{74}$. On ne peut pas comprendre pourquoi les gens ont pu y être attirés à l'époque sans sérieusement tenir compte de leur religion comme de leur conception de la mort.

Certains résidants ont sûrement subi les inconvénients religieux pour pouvoir profiter des avantages matériels. Ceux qui ne pouvaient endurer ni les règlements, ni la religion, quittaient, et de plus en plus au fur et à mesure que le siècle avançait. Ceux qui restaient savaient qu'ils n'affronteraient pas seuls la mort, un sort craint depuis des siècles $^{75}$. Les soins attentionnés prodigués par les sœurs les assuraient de mourir en bons catholiques après réception des derniers sacrements des mains d'un prêtre. Cette crainte d'une mauvaise mort était un instrument puissant entre les mains de l'Église, et on peut avancer que la relation de pouvoir tissée durant les dernières années de vie des personnes âgées était beaucoup plus une relation de contrôle spirituel que de contrôle social, comme l'ont souvent affirmé des historiens.

Si les sœurs ont sûrement trouvé difficile par moments d'être confrontées aux handicaps, à la sénilité ou à l'obstination de leurs patientes, il n'en demeure pas moins vrai que l'appellation «nos chères vieilles» a des accents affectueux, quoique possessifs. Les vieilles et les malades étaient aussi importantes pour leur vocation de religieuses qu'elles pouvaient l'être pour les Montréalais participant aux dîners des pauvres ou donnant de l'argent pour leur subsistance. Une relation religieuse et économique réciproque unissait ceux qui recevaient à ceux qui donnaient, ceux qui priaient à ceux pour qui on priait, apportant aux uns des bénéfices matériels et aux autres des bénéfices spirituels. En aidant les personnes âgées vivant en institution à faire une bonne mort, les Montréalais qui donnaient de l'argent aux Sœurs de la Providence lorsqu'elles quêtaient de porte en porte pour obtenir de la nourriture pour la communauté et les Dames de Charité qui travaillaient à amasser des fonds dans les bazars ou faisaient de la couture pour les pensionnaires croyaient eux aussi s'assurer une bonne mort.

\section{Traduction: François Dumas et Pierre Trépanier}

73 Faure, «Les classes populaires», 269.

74 Sharon Cook affirme que si les Protestant Old Age Homes for Women and Men d'Ottawa étaient des endroits tranquilles pour mourir, ils visaient aussi à exercer une certaine forme de contrôle social. Il semble que l'aspect spirituel ait eu une importance du même ordre dans les foyers catholiques. «'A Quiet Place... to Die': Ottawa's First Protestant Old Age Homes for Women and Men», Ontario History, 81,1 (mars 1989): 27-28, 38-39.

75 Philippe Ariès, L'Homme devant la mort (Paris, Seuil, 1977). 